\title{
NAS FRONTEIRAS ENTRE O BIOLÓGICO E O CULTURAL, O AFETO
}

Ivone Martins de Oliveira*

RESUMO: Este artigo tem como objetivo apontar algumas contribuiçóes dos estudos de Angel Pino para a compreensão da afetividade numa perspectiva histórico-cultural. As elaboraçóes do autor sobre os modos de articulação entre os planos biológico e cultural no desenvolvimento humano são tomadas como eixo para abordar a temática. Na discussão desenvolvida, são retomadas passagens da construção teórica de Pino em que a relação entre o biológico e o cultural é tematizada, para, a partir dela, apontar algumas reflexóes feitas acerca do plano afetivo, elaboradas em diferentes momentos de sua trajetória acadêmica. Pino nos aponta que um veio de reflexão frutífero é aquele em que o afetivo é abordado no contexto das relaçóes humanas, produçáo social e histórica inscrita na materialidade que nos constitui como humanos e transpassada pela significaçáo.

Palavras-chave: Cultura. Biologia. Afetividade. Significação.

* Universidade Federal do Espírito Santo (Ufes), Centro de Educação. Vitória, ES., Brasil. E-mail de contato: ivone.mo@terra.com.br. 


\title{
On the boundary between the biological and the cultural: affection
}

\begin{abstract}
This paper aims to point out some contributions from Angel Pino's studies for the understanding of affection in a cultural-historical perspective. The author's elaborations on the modes of articulation between the biological and cultural plans in human development are taken as the axis to address the theme. Within the issues in discussion, passages from Pino's theoretical construction are resumed, in which the relation between the biological and the cultural is thematized, so that, to and from it, we can point out some reflections about the affective plan, elaborated in different moments of his academic career. Pino shows us that a fruitful reflection vein is the one that addresses affection in the context of human relations, social and historical production inscribed in the materiality that constitutes us as human beings and permeated by signification.
\end{abstract}

Keywords: Culture. Biology. Affection. Signification.

\section{INTRODUÇÃO}

[...] o homem é, na sua condição originária, uma materialidade viva que o mantém na ordem da natureza. Mas é uma materialidade que se constitui em um ser de outra ordem, a simbólica, como resultado da sua condição, ao mesmo tempo, de sujeito e objeto de sua própria atividade criadora. (PINO, 2006, p. 65-66)

\footnotetext{
citação de Pino diz respeito a uma das preocupaçóes que o acompanhou na abordagem do desenvolvimento humano: a complexa relação entre os planos biológico e cultural - questão com que se depara a Perspectiva Histórico-cultural do Desenvolvimento Humano, a qual tem se colocado a tarefa de compreender o que, no gênero humano, é biológico e o que é cultural e histórico, e como esses dois planos se articulam.
} 
Ao acompanhar parte da trajetória acadêmica do autor, notamos que suas elaboraçóes e contribuiçóes para o estudo do desenvolvimento humano foram além do que temos acesso a partir de textos que ele publicou. Um dos temas abordados por ele em aulas, sobretudo, de graduaçáo, diz respeito à afetividade, de modo geral, apoiado em um texto que ele não publicou - Ontogênese da relação humana -, mas que tem sido tomado como referência em diferentes estudos sobre a afetividade, entre eles, Oliveira (2001), por conta das contribuiçóes que traz para a compreensão do plano afetivo que atravessa e constitui as relações humanas. Porém, observamos que esse texto incorpora apenas parcialmente contribuiçóes de estudos realizados por Pino no âmbito da matriz histórico-cultural, especialmente a partir da década de 1990.

Diante disso, neste artigo, é nosso objetivo apontar algumas contribuições das pesquisas do autor para a compreensão do plano afetivo numa perspectiva histórico-cultural. Para esta discussão, inicialmente abordaremos brevemente passagens da construçáo teórica do autor em que a relação entre o biológico e o cultural é tematizada, para, em seguida, trazer alguns apontamentos e reflexóes acerca do afetivo, elaborados por ele em diferentes momentos de sua trajetória acadêmica.

\section{APONTAMENTOS ACERCA DAS ELABORAÇÕES TEÓRICAS DE PINO}

Apresentamos a seguir uma breve síntese da construção do pensamento de Pino sobre o desenvolvimento cultural do homem, a partir de textos produzidos por ele entre 1991 e 2013, de forma a situar suas contribuiçóes para a abordagem do universo afetivo. Ao discorrer sobre diferentes temas, o autor dialoga com autores distintos, porém, considerando nosso interesse pelo desenvolvimento humano e, particularmente, pela dimensão afetiva, procuraremos nos deter no diálogo estabelecido com os estudos de Karl Marx, Lev Semionovich Vigotski, Mikhail Bakhtin e Henri Wallon.

Desde a década de 1980, Pino teve contato com textos de autores da chamada, à época, "psicologia soviética" e, a partir disso, desenvolveu estudos que culminaram com sua participação na composição 
do n. 24, ano 1991, dos Cadernos Cedes - Pensamento e linguagem: estudos na perspectiva da psicologia soviética - que foi um marco na abordagem das ideias de autores como Vigotski e Bakhtin no Brasil. Nesse texto, Pino trata da mediação semiótica na obra de Vigotski e de seu papel na constituiçáo do psiquismo humano. Entre os anos de 1991 e 1993, observamos, na produção do autor, a ênfase na abordagem da base marxista sob a qual se assentam os estudos desses pesquisadores. As contribuiçóes das ideias de Karl Marx e de Friedrich Engels acerca do papel do trabalho na constituição do gênero humano, das bases material e social da vida humana, consubstanciadas nas análises das relaçóes e nas práticas sociais que caracterizam a sociedade capitalista, bem como do próprio método dialético são destacadas e serão reiteradamente abordadas em textos produzidos posteriormente, quase sempre com elaboraçóes caracterizadas por uma crescente densidade teórica. Pino leu a obra de Vigotski e de Bakhtin pelos olhos de Marx, o que lhe conferiu uma atenção especial à base materialista da constituição do psiquismo e uma constante preocupação com a relaçáo entre o biológico e o cultural em seu desenvolvimento. Conforme destaca Pino (1993a, p. 56):

O psiquismo animal não transcende a realidade orgânica, enquanto no caso humano o funcionar orgânico é condição e suporte das funções psíquicas [...]. Tais funçôes apoiam-se no funcionar orgânico, mas o que elas póem em ação não é da ordem do orgânico [...].

$\mathrm{O}$ que as funçôes psíquicas superiores colocam em ação é a significação, reafirma o autor, apoiado nas obras de Vigotski e de Bakhtin. Do significado da palavra como unidade de análise do pensamento à compreensão do caráter ideológico do signo linguístico, Pino encontra elementos para abordar a natureza semiótica - e histórica - do psiquismo: o signo, em especial a palavra, é instrumento de constituiçáo das formas tipicamente humanas de pensar, de agir e de sentir. Porém, se ele reconhece o papel da linguagem nesse processo, reportando-se à obra de Vigotski, alerta para o fato de que "[...] a linguagem não esgota os processos de produção de significação, ou seja, do campo da semiótica [...]". (PINO, 1993b, p. 20) E é com essa preocupação que ele se dedicará à 
leitura de produçóes de Charles S. Pierce acerca de uma estrutura semiótica do tipo triádico, constituída pela relação entre o signo e o objeto, mediada pelo elemento que está na base dessa relação - o interpretante.

Em 1996, Pino produz um artigo muito interessante que enfoca conceitos importantes para a abordagem da constituição do sujeito. Vemos nesse texto indícios de um movimento significativo de operar com os conceitos teóricos na compreensão da constituição social e histórica da pessoa, o que terá repercussôes significativas na abordagem do domínio afetivo. Pino leu Concrete Human Psychology, traduzido para o português como Manuscrito de 1929 (VIGOTSKI, 2000) e esse texto propiciou a ele elementos para novas elaboraçóes acerca da constituição do sujeito e da significação, além da possibilidade de ampliar suas análises sobre o plano afetivo. Para o autor, a tese da

[...] natureza cultural do homem, tal como é proposta por Vigotski, revela que a subjetividade, expressão da realidade da pessoa, é uma reconstituiçáo singular, na esfera privada, do drama da intersubjetividade humana que ocorre na esfera pública das relaçôes sociais [...]. (PINO, 1996, p. 12)

Problematizando o termo internalização para tratar da relação entre os planos inter e intrapsíquicos, pelo fato de este sugerir interpretaçóes topológicas, como interno ou externo, dentro ou fora, Pino já se reporta, nesse texto, ao termo conversáo, também utilizado por Vigotski, alhures, para se referir ao processo de transmutação das relaçóes sociais em funçóes psicológicas, acompanhado dos conceitos de esfera pública e esfera privada, em lugar de planos inter e intrapsicológicos; o termo conversão permite não somente remeter ao processo de mudança de um estado a outro, como também considerar o que subsiste no movimento de transmutação das relações sociais em funções psicológicas, que é a significação, ainda que esta também passe por alteraçóes nesse processo de conversão. Além de operar com os conceitos de mediação semiótica e de polifonia, suas análises indicam, ainda, a pertinência de trazer as contribuiçóes de Wallon a respeito da relação eu-outro para abordar o contexto intersubjetivo na constituição da pessoa. Para além de uma 
perspectiva idealista e subjetivista que tem caracterizado os estudos da categoria pessoa, Pino a concebe a partir das elaboraçóes de Vigotski: um "agregado de relaçóes sociais", noção emprestada de Marx.

Porém, trabalhar com essa noção coloca ao autor a necessidade de aprofundar a discussão de outros aspectos, considerando seu interesse pela questâo do sujeito: sendo a pessoa um agregado de relaçóes sociais convertidas da esfera pública para a privada, e delineando-se as relaçóes sociais como universo múltiplo e contraditório, perpassado por funçóes e posiçóes diversas ocupadas por essa pessoa numa dada formação social, o processo de conversão necessariamente refletirá, na esfera privada, o conflito de diferentes perspectivas, interesses e desejos em jogo no drama delineado. Nesse contexto, o drama traz a ideia do outro que penetra no eu e que se torna parte integrante desse eu - o outro das relaçóes sociais que constituem o plano intrasubjetivo, outro que afeta e configura o próprio drama. Vemos, assim, o drama como um conceito potente para a abordagem do afetivo no contexto das relaçóes humanas.

Em 1997, em um texto produzido em coautoria com Ana Luiza Smolka e Cecília Rafael de Góes, Pino reporta-se à noção de alternância de papeis desenvolvida por Wallon e ao princípio dialógico, de Bakhtin, conferindo mais densidade teórica à abordagem da noção de drama. (SMOLKA; GÓES; PINO, 1997) A partir da análise de uma situaçáo observada entre crianças em interação, numa unidade de educação infantil, os autores reportam-se aos conceitos de polissemia, polifonia e contexto multifacetado da relação com o outro, marcado também por jogos de poder e conflitos, para tratar do universo intersubjetivo na constituição dos sujeitos.

Assim, consideramos que o autor traz uma contribuição importante à compreensão de uma das muitas passagens apenas anunciadas no Manuscrito de 29 - mas não desenvolvidas -, ao buscar elucidar o termo função, utilizado por Vigotski quando trata do desenvolvimento social da personalidade e do drama. Em um texto produzido em 1997, destaca:

[...] internalizar as funçôes da interação social, nos termos em que fala Vygotsky, é internalizar a significação dessas relaçóes, ou, em outros termos, internalizar a 
significação das respectivas posiçôes na relação social e dos papéis delas decorrentes [...]. (PINO, 1997, p. 9)

Considerando a base materialista histórico-dialética, ao tratar do homem como um ser genérico, Pino enfatiza sua inserção nas relaçôes sociais e nas práticas sociais, acontecimento fundamental à sua constituição como homem. Nesse contexto, a definição que apresenta de práticas sociais auxilia numa compreensão mais aprofundada do processo de conversão das relações sociais em funções psíquicas:

Sem pretender dar uma definição do que sejam as práticas sociais, pode-se dizer que elas traduzem, de maneira concreta, as relaçóes sociais em que as pessoas estão envolvidas. Elas são formas socialmente instituídas de pensar, de falar e de agir das pessoas em função das posiçôes que ocupam na trama das relaçôes sociais de uma determinada formação social. Dois aspectos parecem caracterizar as práticas sociais em relação a outras açôes: terem uma certa configuração (o que as torna identificáveis), perpetuarem-se em um certo tempo e em um certo espaço e veicularem uma significação compartilhada pelos integrantes de um grupo social específico. (PINO, 2000, p. 53)

Assim, é a partir de sua inserção nas práticas sociais que o recém-nascido vai se distanciando do plano puramente biológico e se constituindo como um ser cultural, vai se desvencilhando das leis puramente biológicas e imergindo no universo orientado pela cultura, que vai tornando os seus modos culturalmente delimitados de se afetar com e pelo outro e pelos acontecimentos do mundo. Em As marcas do humano: às origens da constituição cultural da criança na perspectiva de Lev. S. Vigotski, publicado em 2005, Pino volta-se para os percursos vivenciados pelo bebê nos primeiros meses de inserção na cultura e aponta alguns aspectos muito interessantes para a abordagem da relação entre o biológico e o cultural. Buscando identificar a base material da qual emergem as funçóes psíquicas superiores, volta-se para estudos das áreas da biologia e da neurologia, detém-se no equipamento genético e neuro- 
lógico da espécie e, a partir de resultados de pesquisas do neurocientista Jean-Pierre Changeux, trabalha com a hipótese de que a cultura deixa marcas no encéfalo humano no curso da ontogênese: "A continuação, por longo tempo após o nascimento, da proliferação sináptica, permite que o tecido cerebral seja impregnado, de maneira progressiva, pelo meio ambiente, físico e social [...]". (CHANGEUX apud PINO, 2005, p. 155) Papel importante nesse processo tem o equipamento sensorial, pelo qual são captados os sinais físicos e químicos que advêm do meio e do impacto que este provoca no organismo e dos quais se originam imagens mentais. Conforme comenta Pino (1998):

Recebemos uma herança biológica que, a partir de certo momento sofre interferências que alterarão a sua estrutura genética. Por intermédio da percepção, há uma captação de estímulos que, ao que tudo indi$\mathrm{ca}$, formam imagens (as imagens parecem se formar a partir de um processo bioquímico instalado no cérebro). Há uma produção automática no contato do organismo com o meio. A imagem abordada aqui não é sinônimo de fotografia: a imagem é a 'coisa em mim'; a fotografia é a 'coisa em si'. Há imagens de diversos tipos. As imagens são singulares, mas são complexas. Elas vêm como um todo que envolve tudo aquilo que foi captado num quadro multidimensional. A imagem é a forma mais primitiva de acesso ao real. O sujeito não capta o real, mas sim imagens do real caótico, as quais são organizadas a partir de um modelo explicativo da cultura. O imaginário é como uma "fábrica" que trabalha com matéria-prima que está dada - as imagens. Esta matéria prima pode ser combinada das mais variadas formas; entretanto, para isto, precisa da capacidade de representação. A articulação das imagens só é possível pelo simbólico (anotações de aula).

As elaboraçôes sobre essa imagem Pino aprofunda em texto publicado em 2006, ao tratar do sentido estético, trazendo, inclusive, a contribuição das pesquisas do neurocientista Antonio Damásio relativas às alterações bioquímicas produzidas no cérebro a partir das imagens 
formadas. No entanto, ainda que essas imagens auxiliem na compreensão da articulação entre o biológico e o simbólico, elas são apenas parte do caminho que conduz a esse plano simbólico, pois não permitem ultrapassar os limites da percepção sensorial. "Transpor esses limites pressupóe a capacidade de ver a realidade num outro plano, aquele em que à imagem mental do homem contrapõe uma representação simbólica [...]", aponta Pino (2005, p. 158).

Do sensorial à imagem mental, da simples reprodução da realidade à representação simbólica dessa realidade, um complexo percurso se desenha, demandando investimento em pesquisas de áreas distintas, de maneira a desvendá-lo. A despeito dos estudos realizados até o momento, a passagem do plano natural das funçóes biológicas ao plano cultural das funçôes simbólicas ainda se constitui num objetivo a ser perseguido por novas investigaçóes. É provavelmente com esse interesse que Pino se reporta, também, ao aprofundamento de leituras de Charles Darwin, tentando apreender de sua obra o que ela permite em termos de problematizaçóes e avanços na compreensão do processo pelo qual o homem assume o controle da própria evolução e constrói sua história. (PINO, 2009, 2013) Que o equipamento genético e sensorial deve ser tomado como a base das funções psíquicas superiores Pino concorda, mas, retornando a Vigotski, lembra também que esse substrato biológico se organiza em uma pessoa, unidade psíquica que conhece, pensa, age e é impactada pelos acontecimentos do mundo de uma maneira singular, perspectiva a partir do qual se devem abordar os processos psíquicos: "Com as mesmas leis de pensamento [...], o processo será diferente, dependendo de em qual pessoa ele acontece [...]”. (VIGOTSKI, 2000, p. 33)

Nessa breve retomada de uma parte da extensa produção de Pino, destacamos suas reflexóes acerca da elucidação e, mais que isso, da articulação de conceitos teórico-filosóficos na direção de uma compreensão de como a cultura e a história se inscrevem em nós, marcam nossos corpos, talham nossas consciências, significando-os para além da materialidade orgânica que nos constitui. Como situar o afetivo nesse contexto? 


\section{CONTRIBUIÇÕES TEÓRICO-CONCEITUAIS DOS ESTUDOS DE ANGEL PINO PARA UMA ABORDAGEM DA AFETIVIDADE NUMA PERSPECTIVA HISTÓRICO-CULTURAL}

Inicialmente, é importante ressaltar que, no texto Ontogênese da relação humana, os fenômenos afetivos são compreendidos como “[...] experiências subjetivas que traduzem a maneira como cada sujeito é afetado pelos acontecimentos da vida, ou melhor, pelo sentido que tais acontecimentos têm para ele [...]”. (PINO, [198-], p. 128) Percebemos nesse enunciado a significação se delineando como um componente constituidor dos fenômenos afetivos.

De forma semelhante a Vigotski, Pino afirma que as leis gerais do desenvolvimento também se aplicam ao domínio afetivo. Alicerçado nos estudos vigotskianos, levanta a hipótese de uma base biológica também para o afeto:

O afeto tem relação com a significação que a emoção coloca "em mim". O afeto é uma realidade orgânica, psíquica, cultural, mas que se expressa por intermédio da semiose, da produção de sentidos possíveis [...]. (PINO, anotaçôes de aulas, 1998)

Para o autor, a afetividade, como uma entidade, não existe, ela é uma "qualidade da relação" e envolve aquilo que o sujeito percebe como significativo nessa relação. É nesse sentido que Pino destaca que, entre os acontecimentos do mundo que afetam a pessoa, "[...] as atitudes e as reaçôes dos seus semelhantes a seu respeito são, sem sombra de dúvidas, os mais importantes, imprimindo às relaçóes humanas um tom de dramaticidade [...]". (PINO, [198-], p. 130) Inserindo-se no universo das relaçôes humanas, a afetividade implica a existência de vínculos, que, possivelmente, teriam surgido na história da espécie a partir de uma necessidade biológica de contato. No contexto das relaçôes sociais, nem todas as formas interativas, por si sós, garantem o vínculo, mas é a partir delas que este pode se consolidar. E, nessa discussão, os postu- 
lados vigotskianos acerca do plano intersubjetivo trazem contribuiçóes relevantes.

Assim, a tese de que o biológico se transforma no simbólico estende-se também à emoçáo, que se transforma com o desenvolvimento da linguagem. Em sua origem,

A emoção é da ordem da imagem, é da ordem do sinal, é da ordem do biológico, o que faz dela uma reação biológica não representada, não elaborada. No processo de desenvolvimento, o componente biológico é pego pela linguagem [...]. (PINO, anotações de aula, 1998).

A palavra, como signo, "prende o imaginário", fornecendo à emoção contornos próprios e possíveis nos limites do dizer.

A emoçáo é anterior à fala, anterior a qualquer forma de linguagem. Por quê? Porque é radical, é originária, é o que nos une aos nossos antepassados. Porém a partir do momento em que quem é afetado se sente afetado... ele... já mudou tudo. Tudo indica que, a menos que haja descobertas extraordinárias, que o animal... ele sente, mas não sabe que sente. Agora a criança pequenininha sente e sabe que sente, mas não sabe dizer o que sente. Por quê? Porque dizer o que sente implica todo um trabalho de passar para o simbólico, algo que, embora se manifeste, é algo fundamentalmente da ordem do imaginário. As primeiras formas simbólicas não são necessariamente a linguagem [...] Agora, para dizer o que sente, é preciso da linguagem. (PINO, anotaçôes da arguição durante exame de qualificação de doutorado, em 2000)

O simbólico envolve, dá forma, (re)constitui o biológico num novo plano e, nesse contexto, a palavra dá forma à emoção vivenciada. Se considerarmos que "dizer", constituir-se/expressar-se por meio da linguagem é o que define o homem, na medida em que ele não é capaz 
de dizer/significar, ele não teria emoção, num sentido especificamente humano, tal qual ocorre com o animal. Afirma Pino que, por vezes, nós atribuímos emoção aos animais, mas na medida em que eles operam em um nível que não há representação, não há signo, pode-se dizer que eles têm movimentos, reaçôes, mas não propriamente emoções, no sentido humano do termo, pois estas implicam a significação. Porém, temos aqui outra ordem de questóes a enfrentar: a relação entre sentir e significar.

Comentando sobre o estado emocional do atleta no jogo de tênis, Pino reporta-se à explosão emocional, manifestada por gestos, gritos e berros, que resulta do sentir que o contexto do jogo traz e aponta que, nesse momento, "[...] esse sentir, essa percepção do significado que está em jogo não é facilmente controlável [...]. Por quê? Porque, nesse momento, é todo o ser orgânico que está envolvido na ação". (PINO, anotações da arguição durante exame de qualificação de doutorado, em 2000) O autor retoma aqui uma ideia defendida também por Wallon (1995) para quem a emoção pode obnubilar a atividade representativa. Nesse contexto, o sentir refere-se à significaçáo/modo de conceber o jogo pelo atleta. Entretanto, é pertinente indagar, neste momento, se seria possível ao sujeito desdobrar esse modo de conceber a partir da maneira como ele é afetado do ponto de vista orgânico pelo contexto do jogo; o conjunto das alteraçóes neurofisiológicas desencadeado no corpo também é sentido pelo atleta e compôe a significação que atravessa e constitui a emoção como um fenômeno tipicamente humano.

A esse respeito, Pino sugere uma diferenciação entre significar e ser afetado pela significação.

Quando a gente fala do sentido, entre outras coisas, é a significação sentida ... se essa significação não me afeta ... Se alguém olha para mim e diz "Você está péssimo!" e isso não me afetar em nada, eu entendo "estar péssimo" como estar péssimo e acabou. Agora se isso me afeta porque estou me vendo doente ou velho, aí estou sentindo a significação desse discurso. (Anotaçôes da arguição durante exame de qualificação de doutorado, em 2000) 
Nesse contexto, o autor levanta a hipótese de diferentes níveis de significação:

Há diferentes níveis. Diferentes no nível mais próximo, digamos, do biológico, mas não é biológico, só, mas mais próximo... do que no nível mais alto do simbólico. Eu acho que há um espectro aí, de níveis diferentes de significação [...] (Anotações da arguição durante exame de qualificação de doutorado, em 2000).

Em 2006, ele apresenta uma compreensão mais elaborada dessa temática, ao distinguir três níveis de análise da questão estética, no que diz respeito ao termo "sentido": o primeiro em que se destaca o orgânico e se desdobra na dimensão sensorial, por um lado e, por outro, na "[...] impressão produzida pela percepçáo dos objetos do mundo exterior ou dos acontecimentos da vida: é daí que decorre o termo 'sentimento"' (PINO, 2006, p. 66); o segundo tem um caráter de direção, indica a direcionalidade de um processo ou evento; e o terceiro é semiótico, referente à significação das coisas, à criação e interpretação de símbolos.

Assim podemos dizer que a significação atribuída ao modo como somos afetados pelos acontecimentos do mundo, com os infindáveis matizes que nossa materialidade orgânica possibilita, passa inexoravelmente pelo outro, pela palavra e pelo contexto histórico e cultural em que essa relação se constitui

\section{CONSIDERAÇÕES FINAIS}

Diante de uma tradição que aborda o sujeito em uma perspectiva dualista em que corpo e mente, sensibilidade e razão, biologia e cultura encontram-se cindidos, temos dificuldade em conceber o afetivo, uma dimensão aparentemente tão íntima e singular, como produção social e histórica. Entendemos que as elaboraçôes de Pino, a partir do diálogo estabelecido com autores alinhados com a matriz histórico-cultural, trazem contribuiçóes significativas para aqueles que se dispuserem 
a enveredar por esse caminho tão fascinante, e ao mesmo tempo sinuoso, que é o da abordagem do universo afetivo. Pino nos aponta que um veio de reflexão frutífero é aquele em que o afetivo é abordado no contexto das relaçóes humanas, produçóes social e histórica inscritas na materialidade que nos constitui como humanos. Materialidade que, em si, pode abrigar estados de bem-estar ou de mal-estar; mas que, orientada para e pelo outro, por meio do signo, transmuta, significa, pode produzir alegria ou tristeza, amor ou ódio - ou, também, profunda saudade.

\section{REFERÊNCIAS}

OLIVEIRA, I. M. O sujeito que se emociona: signos e sentidos nas práticas culturais. 2001. 188f. Tese (Doutorado em Educação) - Faculdade de Educação, Universidade Estadual de Campinas, Campinas, 2001.

PINO, A. Ontogênese da relação humana. Campinas, [198-]. (mimeografado).

. O conceito de mediação semiótica em Vygotsky e seu papel na explicação do psiquismo humano. Cadernos Cedes, Campinas: Papirus, n. 24, p. 32-43, 1991. [Dossiê Pensamento e Linguagem: estudos na perspectiva da psicologia soviética].

. A interação social: perspectiva sócio-histórica. Revista IDEIA. São Paulo, n. 20, p. 49-58, 1993a.

. Processos de significação e constituição do sujeito. Temas em Psicologia, Ribeirão Preto, v. 1, n. 1, p. 17-24, 1993 b.

. Constituiçáo e modos de significação do sujeito no contexto da pré-escola. In: PEDROZA, M. I. (Org.). Investigação da criança em interação social. Coletânea da ANPEPP. Recife: Editora Universitária, UFP, 1996. p. 11-32.

- Natureza e cultura: as funçóes naturais na constituição cultural do homem. In: SMOLKA, A. L. B.; NOGUEIRA, A. L. H. (Orgs.). Estudos na perspectiva de Vigotski: gênese e emergência das funçóes psicológicas. Campinas: Mercado de Letras, 2013, p. 71-98.

- Ciência e educação: a propósito do bicentenário do nascimento de Charles Darwin. Educ. Soc., Campinas, v. 30, n. 108, p. 845-866, 2009. Disponível em: <http://ref.scielo.org/6qhjtp>. Acesso em: 25 maio 2015. 
PINO, A. A produção imaginária e a formação do sentido estético. Reflexóes úteis para uma educação humana. Pro-Posiçóes, Campinas, v. 1, n. 1, p. 47-70, 2006.

. As marcas do humano: às origens da constituição cultural da criança na perspectiva de Lev S. Vigotski. São Paulo: Cortez, 2005.

. A psicologia concreta de Vigotski. In: PLACCO, V. M. N. S. (Orgs.). Psicologia \& Educaçâo: revendo contribuições. São Paulo, 2000a. p. 33-61.

. A questão cultural na perspectiva histórico-cultural de psicologia. In: CONGRESSO INTERAMERICANO DE PSICOLOGIA, 26., 1997. Resumos... São Paulo: [s.n.], 1997.

SMOLKA, A. L. B.; GÓES, M. C. R.; PINO, A. La constitución del sujeto: una cuestión persistente. In: WERTSCH, J. V.; DEL RIO, P.; ÁLVAREZ, A. (Eds.). La mente sociocultural: aproximaciones teóricas y aplicadas. Madrid: Fundación Infancia y Aprendizaje, 1997, p. 129-142.

VIGOTSKI, L. S. Manuscrito de 1929. Educ. Soc. Campinas, n. 71, p. 21-44, jul. 2000. Disponível em <http://ref.scielo.org/n6jckf>. Acesso em 25 maio 2015.

WALLON, H. As origens do caráter na criança. São Paulo: Nova Alexandria, 1995.

Recebido em 15 de junho de 2015.

Aprovado em 30 de julho de 2015.

DOI: http://dx.doi.org/10.1590/CC0101-32622015V35ESPECIAL154117 